\title{
Smooth Operating: A Structural Analysis of Social Behavior (SASB) Perspective on Initial Romantic Encounters
}

Social Psychological and

Personality Science

I(4) 344-352

(C) The Author(s) 2010

Reprints and permission:

sagepub.com/journalsPermissions.nav DOI: $10.1177 / 1948550610373402$ http://spps.sagepub.com

@SAGE

\author{
Paul W. Eastwick', Seema D. Saigal ${ }^{1,2}$, and Eli J. Finkel ${ }^{2}$
}

\begin{abstract}
The present report used the comprehensive structural analysis of social behavior (SASB) observational coding scheme to examine which behaviors differentiate smooth from awkward initial romantic encounters. Participants on speed-dates rated as smooth (by independent observers) behaved more warmly and were more other-focused than participants on awkward dates. In addition, participants on smooth dates tended to avoid extremes on the autonomy dimension, exhibiting neither strong independence from nor strong interdependence with their speed-dating partners. Furthermore, the manner in which participants were self-focused (but not other-focused) reliably differentiated smooth from awkward dates; that is, date smoothness strongly predicted how participants reacted to their speed-dating partners (type of self-focus) but only weakly predicted how participants acted toward their speed-dating partners (type of other-focus). Finally, the authors note SASB's potential to serve as an overarching framework that explains why some interactions go well and others do not.
\end{abstract}

\section{Keywords}

interpersonal processes, communication, dating, interaction quality, SASB

Like moss, a person can grow on you over time. Maybe he fails to make a spellbinding first impression, but as the days and weeks pass, you come to see him in a different light, liking him more and more. Countless romantic relationships begin this way, and this script may inspire optimism during lonelier times for those who do not have a gift for captivating people's attention on an initial encounter. Indeed, such smooth initial interaction is all too elusive for many people. What morsels of small talk will keep an interaction partner engaged, and what techniques best keep a conversation flowing? People with a gift for smooth interpersonal interaction seem to intuit the answers to these questions, but only rarely does that gift translate into concrete advice for those who lack it.

This report examines young adults' behaviors during an initial interaction with a potential romantic partner in an attempt to illuminate which behaviors make for a smooth versus an awkward interaction. People are highly motivated to get along with interaction partners - "to have smoothly flowing and pleasing interactions" (Snyder, 1992, p. 74; also see Goffman, 1959; Jones, 1990). In fact, the goal of getting along is primary in initial interactions; participants default to it over the goal of learning accurate information about an interaction partner (Snyder \& Haugen, 1995). We follow these scholars in using the term smooth (along with its conceptual antithesis awkward) to refer to the extent to which the getting along goal is achieved in an interaction. Indeed, smoothness is perhaps the central component of communication quality, and it correlates highly with conversational satisfaction and attraction to one's interaction partner (Duck, Rutt, Hurst, \& Strejc, 1991; Sprecher \& Duck, 1994).

Yet despite the importance of getting along in an initial encounter, psychological science does not yet have strong prescriptions regarding the specific behaviors that make for smooth first dates, although recommendations abound in the popular press. For example, according to The Rules, women should avoid reciprocating men's positive overtures in the early stages of a relationship (Fein \& Schneider, 1995), and selfproclaimed pickup artists (Strauss, 2005) claim that men can make themselves more attractive to women using the "neg"-a belittling comment masquerading as a compliment. As scholars, we do not wish to cede this ground to nonempirical speculation, and so the present analysis uses objective thirdparty codings of videotaped speed-dating events to demonstrate that certain behaviors are more or less likely to characterize

\footnotetext{
' Texas A\&M University, College Station, TX, USA

${ }^{2}$ Northwestern University, Evanston, IL, USA

Corresponding Author:

Paul W. Eastwick, Texas A\&M University, 4235 TAMU, College Station, TX 77843

Email: p-eastwick@northwestern.edu
} 
smooth initial encounters. In this endeavor, we draw on the structural analysis of social behavior (SASB; Benjamin, 1974), a broad coding tool and conceptual framework that allows us to "map the domain" of initial romantic interaction.

\section{Smooth Interactions in Empirical Psychology}

In an ideal world, all of our social interactions would be smooth and seamless, yet coordination missteps frequently thwart this ideal (Finkel et al., 2006). What specific behaviors facilitate smooth, pleasant interactions? Interpersonal warmth versus hostility (Leary, 1957) is one relevant psychological dimension. For example, warm people tend to have initial interactions of higher self- and observer-rated quality (Berry \& Hansen, 2000). Furthermore, expressions of warmth tend to elicit warmth from interaction partners in turn (Markey, Funder, \& Ozer, 2003), and such affiliative cues lead interaction partners to want to meet again in the future (Sunnafrank, 1988). Similarly, negative affect is a powerful predictor of unpleasant interactions in established couples (Gottman \& Levenson, 1992), and couples who exhibit affiliative cues during a conflict discussion are more likely to engage in behaviors that reduce conflict (Gonzaga, Keltner, Londahl, \& Smith, 2001). Under most imaginable circumstances, interpersonal warmth will likely make for a smoother, more pleasant interaction than will hostility.

A smooth interaction could also be facilitated by the extent to which one behaves interdependently with versus independently from one's interaction partner. Research on initial interactions reveals that people tend to like each other as they disclose more (Collins \& Miller, 1994; Sedikides, Campbell, Reeder, \& Elliot, 1999), especially when those disclosures are intimate (Aron, Melinat, Aron, Vallone, \& Bator, 1997). Thus, too much psychological distance in an initial interaction could be perceived as unfriendly or even rejecting. However, strangers tend not to disclose especially personal information in an initial encounter; people prefer safe, casual topics at first and wait for a relationship to progress before delving into more intimate topics (Altman \& Taylor, 1973). In fact, some (i.e., anxiously attached) people have a tendency to disclose too much personal information when they are exhausted, and such excessive disclosure can come across as needy or neurotic (Vohs, Baumeister, \& Ciarocco, 2005). Overall, prior research on disclosure suggests that smooth interactions are characterized by some balance between independent aloofness and excessively intimate disclosure.

Another component of pleasant interpersonal interaction concerns the focus of attention: the partner versus oneself. When meeting someone new, it is common for people to ask questions of and make statements that focus on their interaction partner in an attempt to learn more about that person. But too much (or the wrong kind of) other-focus can come off like an interrogation and make one's interaction partner feel ill at ease. Also fraught with pitfalls is the manner in which one focuses on the self during an initial interaction. Early work on self-presentation found that people typically try to convey a positive image to strangers and that this strategy is often effective, as long as their claims are not implausible (Schlenker \& Leary, 1982; Sedikides, 1993). So some amount of self-focus during an initial interaction could be an effective strategy. However, excessively immodest self-presentation around acquaintances and friends is less normative (Tice, Butler, Muraven, \& Stillwell, 1995); whenever one hopes for future interaction with someone (as is certainly the case with a desirable potential romantic partner), one must take care not to appear conceited (Jones \& Wortman, 1973). Thus, it is unclear whether smooth versus awkward romantic interactions are differentiated by (a) the degree of participants' self- versus otherfocus or (b) the manner or style of participants' self- versus other-focus.

\section{SASB}

One method of identifying the predictors of pleasant social interaction would be to design targeted studies that test whether a particular strategy (e.g., favorable self-presentation; Tice et al., 1995) or behavior (e.g., mimicry; Chartrand \& Bargh, 1999) of a priori interest is more likely to characterize smooth versus awkward interactions. An alternative method is to take a broad and comprehensive approach, analyzing every thought that interaction partners verbalize within a single, coherent framework. We adopted the latter approach in this report by coding initial romantic encounters using the micro-analytic ("unit-coded") SASB observational coding scheme (Benjamin, 1996b; Benjamin \& Cushing, 2000; Florsheim \& Benjamin, 2001). SASB is a useful conceptual tool because it incorporates all forms of interpersonal behavior into a theoretically elegant model; it is thus poised to be a major contributor to a growing descriptive psychological science that captures the entire range of consequential human behavior (see Funder, 2009).

The SASB framework categorizes interpersonal behavior according to three dimensions, or axes. The first dimension is affiliation, which ranges from extreme hate to extreme love; it is analogous to the communion or warmth dimension of Leary's interpersonal circumplex (Leary, 1957; Locke, 2000). The second is autonomy, which ranges from extreme differentiation to extreme enmeshment; it is analogous to the construct of independence versus interdependence (Singelis, 1994). The third dimension is the focus of the behavior: other versus self. The affiliation and autonomy dimensions are conceptually continuous, and the two of them combine to form a circumplex. We describe SASB codes in this report using the simplified one-word model (Benjamin, 1996b), which carves the affiliation by autonomy circumplex into eight sections, with each section corresponding to a particular code (see either circumplex in Figure 1). Two of these codes correspond to the extremes, or poles, of the affiliation dimension (extreme hate and extreme love, at the left and right of each circumplex) and are neutral on the autonomy dimension. Similarly, two of these codes correspond to the poles of the autonomy dimension (extreme differentiation and extreme enmeshment, at the top and bottom of 


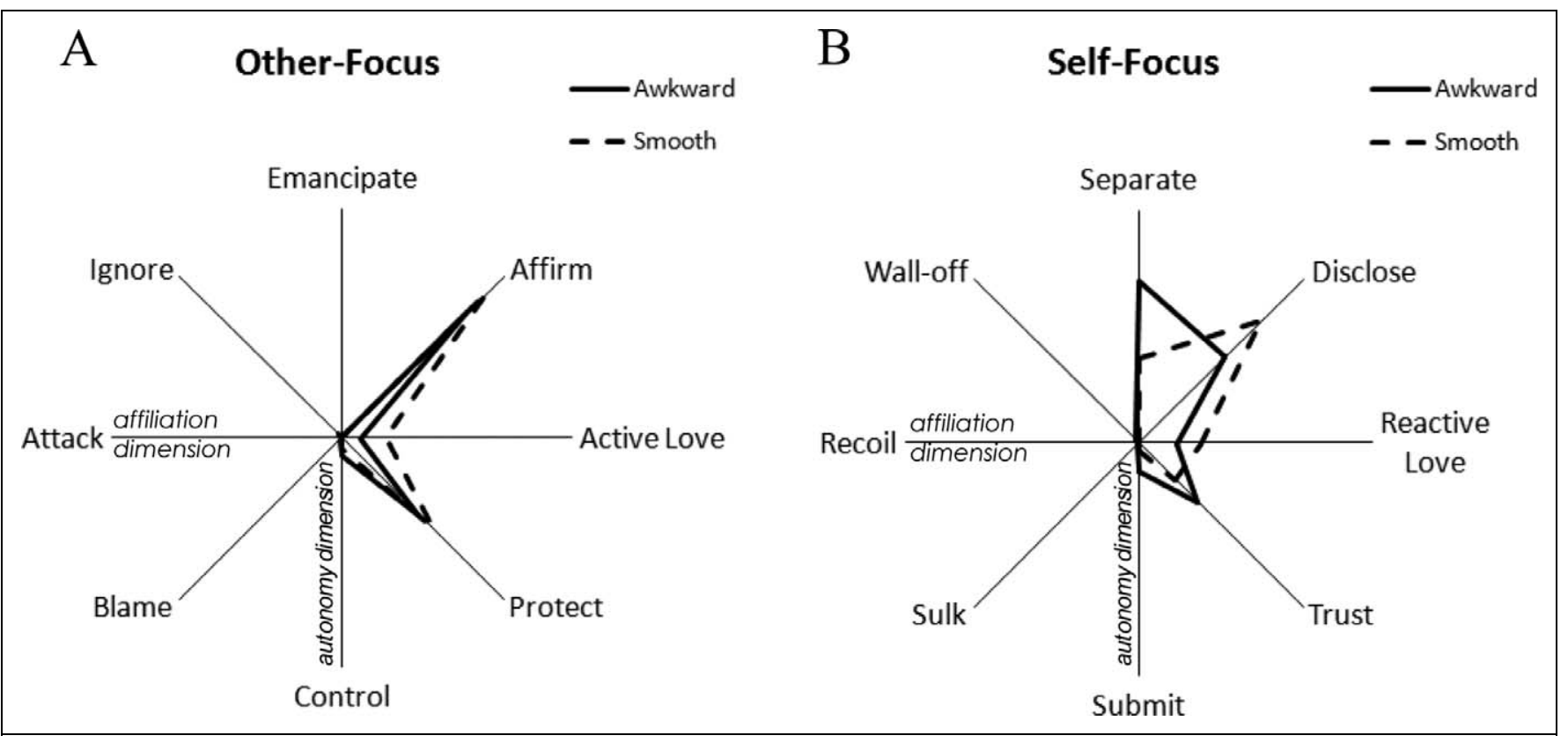

Figure I. Structural analysis of social behavior other-focused (Panel A) and self-focused (Panel B) circumplexes

Note: Lines represent the percentage of codes emerging on the awkward (solid lines) and smooth (dotted lines) speed-dates. The scales of the axes range from $0 \%$ at the origin to $30 \%$ at the end. SASB model used with permission from Guilford Press (Benjamin, 1996b).

each circumplex) and are neutral on the affiliation dimension. The remaining four codes correspond to the four possible combinations of moderate hate versus moderate love and moderate differentiation versus moderate enmeshment.

The third dimension is categorical and indicates the focus of the participant's behavior or statement-in the present study, the two possibilities were the speed-dating partner (otherfocus) and the self (self-focus). In SASB, other-focused codes describe behaviors the participant does to, for, or about the partner; in other words, they indicate the manner in which the participant is acting toward the partner. Self-focused codes describe behaviors the participant does to, for, or about the self; they indicate the manner in which the participant is reacting to the partner. ${ }^{1}$ Trained coders designate each verbalized thought as either self- or other-focused, then, by assessing the degree of affiliation and autonomy in the thought, they assign it to one of the eight positions within the appropriate (i.e., self vs. other) circumplex. Where relevant, statements may be assigned more than one code (i.e., a "complex" code). Thus, each verbalized thought receives at least 1 of the 16 possible codes listed in Table 1.

Studies employing the SASB observational coding scheme have typically focused on clinical topics. For example, one study found that boys at high risk for antisocial behavior engaged in more sulking behavior and less trusting behavior than low-risk boys (Florsheim, Tolan, \& Gorman-Smith, 1996), and in another study, drug-dependent adolescent girls exhibited more attacking and recoiling codes than a sample of control girls (Humes \& Humphrey, 1994). SASB has also been used to study interactions outside of a clinical setting: A study of married couples found that couples who were experimentally assigned to try to persuade each other exhibited more separating and blaming behaviors than couples who were told to merely have a discussion (Brown \& Smith, 1992). To our knowledge, there is no published SASB analysis of initial interactions between unacquainted participants, and thus the present speed-dating data set is both novel territory for SASB and a straightforward extension of SASB research on couples and families.

\section{The Present Research}

In the present study, we used SASB to code participants' behavior on 20 initial romantic encounters that were rated (by independent observers) as smooth and 20 initial romantic encounters that were rated as awkward. Specifically, we conducted a speed-dating study in which undergraduate students had a chance to meet several members of their preferred sex for 4-min speed-dates. (We enabled mutually interested speeddaters to contact one another after the event.) Using audio and video recordings of these 4-min initial interactions, we explored the following two research questions:

1. General SASB dimensions: Regarding SASB's three primary dimensions, do participants on smooth dates behave more warmly, more interdependently, or with more of an other-focus than participants on awkward dates? The prior literature clearly suggests that warmth makes for smoother interactions than does hostility, but it does not make clear predictions regarding autonomy (walling off is unappealing, but too much enmeshment during an initial interaction could be counternormative and intrusive) or other-focus 


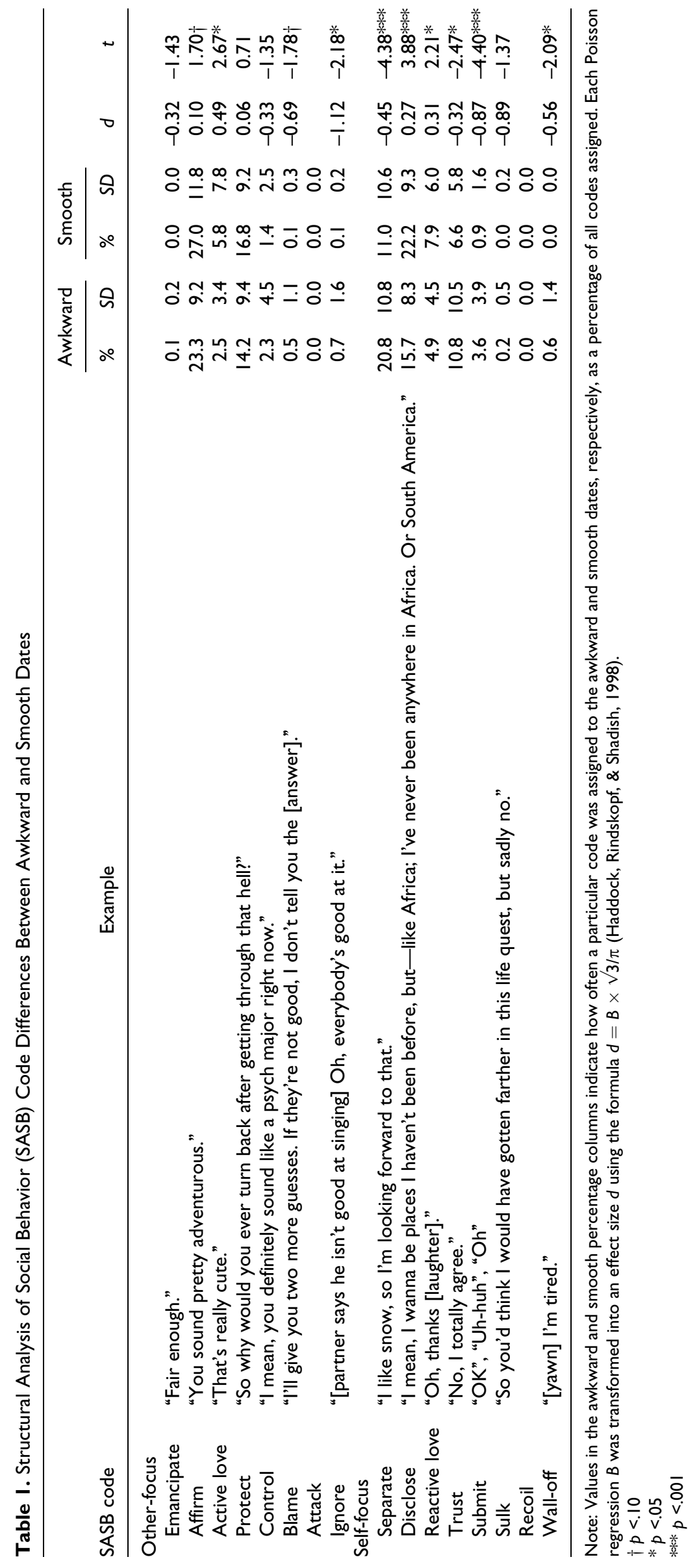


(focusing on oneself could expose one's impressive qualities, but it could also demonstrate discourtesy toward the partner).

2. Specific SASB codes: Do participants on smooth dates behave differently than participants on awkward dates in terms of the 16 specific SASB codes, and do differences primarily emerge on the other or the self circumplex? If it is critical that participants act toward their speed-dating partners in the proper manner, then differences will emerge on the other circumplex, but if it is critical that participants react to their partners properly, then differences will emerge on the self circumplex.

\section{Method}

\section{Participants}

Participants were 80 individuals ( 40 men, 40 women) who took part in speed-dating events on the Northwestern University campus. These individuals were 19.6 years old on average $(S D=1.2)$; the racial/ethnic breakdown was $1 \%$ African American, 15\% Asian, 65\% Caucasian, 4\% Hispanic, 4\% South Asian, and $11 \%$ Other or Multiracial.

\section{Procedure and Materials}

The authors hosted eight speed-dating events in the fall of 2007 to examine a variety of romantic processes. Across all events, 187 heterosexual individuals went on 4-min speed-dates with approximately 12 members of the opposite sex. In total, these individuals went on 1,092 speed-dates, all of which were video and audio recorded. Each date was then viewed once by five to seven trained coders who completed the item "Was the date as a whole awkward or smooth?" (interrater reliability $\alpha=.85$ ) on a 1 (definitely awkward) to 9 (definitely smooth) scale. For the present study, the researchers selected the 20 dates with the lowest scores on this item (awkward dates, $M=3.3$ ) and the 20 dates with the highest scores on this item (smooth dates, $M=$ 7.9) while ensuring that no speed-dater appeared in more than 1 of the 40 selected dates. Supporting of the construct validity of the smooth versus awkward distinction, this variable correlated $r=.50, p=.001$, with a variable indicating whether or not the participants matched (i.e., they "yessed" each other) and $r=$ $.60, p<.001$, with the average of the two speed-daters' reports of romantic desire (e.g., "I was sexually attracted to my interaction partner"). In addition, to make certain that all speed-dating pairs were new acquaintances, the researchers selected dates for which both members of the pair reported (on a questionnaire following each date) a 1 or a 2 to the item "I knew this person very well before today's event" $(1=$ strongly disagree, $9=$ strongly agree).

In the first step of the SASB coding procedure (Benjamin \& Cushing, 2000), trained SASB coders (who did not participate in the awkward versus smooth rating task and were blind to those ratings) watched the speed-dating videos while segmenting the video transcript into separate verbalized thoughts. Participants verbalized an average of $78.11(S D=15.35)$ thoughts on each speed-date ( $M=156.23$ total thoughts per date); speaker turns may consist of more than one verbalized thought. In the second step, at least two trained coders assigned 1 to 3 of the 16 SASB codes to each verbalized thought. ${ }^{2}$ The average number of codes per verbalized thought was 1.14 ( $S D=$ 0.08 ) on both smooth and awkward dates; in other words, complex codes were fairly rare (only $14 \%$ of all verbalized thoughts were complex), and they were no more or less likely to emerge on smooth dates.

The 16 codes are presented in Table 1, along with examples from the speed-dates. The 8 codes on each circumplex range from extremely warm and loving (active love, reactive love) to extremely cold and hateful (attack, recoil); the remaining codes represent intermediate values on this affiliation dimension. The 8 codes on each circumplex also range from extremely differentiated (emancipate, separate) to extremely enmeshed (control, submit); the remaining codes represent intermediate values on this autonomy dimension. The 8 codes on the other circumplex correspond to units in which the other person is the focus of the thought and the 8 codes on the self circumplex correspond to units in which the self is the focus of the thought. The average reliability (calculated on the first 50 codes of each date using Humphrey and Benjamin's, 1989 , weighted algorithm) was $\kappa_{\text {avg }}=.70$, which exceeds the recommended target of .60 (Florsheim \& Benjamin, 2001); all disagreements were resolved by discussion between the coders.

The SASBWorks software (Benjamin, 2000) computes an overall affiliation score and an overall autonomy score for each speed-dater. These overall scores are calculated using a weighting algorithm that accounts for the position of each code on the affiliation and autonomy dimensions; they indicate how warm versus hostile and how differentiated versus enmeshed the speed-dater behaved across the date as a whole. It also computes the proportion of each of the 16 codes for each speeddater (as a percentage of all codes assigned to that speed-dater). Also, we calculated the total percentage of other-focused (vs. self-focused) thoughts to generate an overall other-focus score.

\section{Results}

\section{General SASB Dimensions}

We conducted three analyses to determine whether the smooth versus awkward dates differed significantly on the three main dimensions of the SASB model (affiliation, autonomy, and focus). As each participant is nested within a speed-dating pair, we conducted multilevel regressions that accounted for this statistical nonindependence; the intercept varied randomly. When analyzing the weighted affiliation and autonomy scores provided by the SASB software, smooth dates proved to be significantly warmer than awkward dates, $\beta=.55, t(40)=4.81$, $p<.001$, but the two types of dates did not differ significantly on the autonomy dimension, $\beta=.00, t(40)=0.02, p=.984$. These conclusions were identical when the analyses were conducted only on the other circumplex, affiliation $\beta=.44, t(40)$ $=4.32, p<.001$, autonomy $\beta=.06, t(40)=0.48, p=.634$, and 
only on the self circumplex, affiliation $\beta=.29, t(40)=2.71$, $p=.010$, autonomy $\beta=-.05, t(40)=-0.44, p=.666$. In addition, participants' verbalized thoughts were coded as other-focused significantly more often on smooth dates than on awkward dates, $M_{\text {Smooth }}=51.1 \%, M_{\text {Awkward }}=43.4 \%$, $\beta=.30, t(40)=2.77, p=.008$. No sex differences emerged for these analyses.

\section{Specific SASB Codes}

Next, we conducted separate analyses for each of the 16 specific SASB codes: 8 on the other-focused circumplex and 8 on the self-focused circumplex (Table 1). As the frequencies of several of the codes were quite low and not normally distributed, we conducted multilevel Poisson regression that also accounted for the nesting within speed-dating pair. ${ }^{3}$ These analyses offer a finer degree of behavioral resolution than the macro-dimensional analyses, and they can address whether the differences between the smooth and awkward dates were more likely to emerge when participants were other-focused (i.e., how they acted toward their partners) versus self-focused (i.e., how they reacted to their partners). The extremely hostile attack and recoil codes, although sometimes relevant in conflict settings, never emerged on any speed-date. The smooth versus awkward dates differed on 8 of the remaining 14 codes, with a marginally significant difference emerging for 2 additional codes.

On the other-focused circumplex, participants had significantly more active love codes on the smooth dates. An active love code is a warm, partner-focused statement that communicates no attempt to either control or emancipate the partner; in the speed-dating context, flirting is a prototypical active love behavior. Participants also had significantly fewer ignore codes on the smooth dates. An ignore code is a statement that indicates an active refusal to respond to the partner, often with a cool indifference. Thus, in terms of how participants acted toward their speed-dating partners, dates were smoother to the extent that participants made warm gestures that were intermediate on the autonomy dimension and did not actively neglect their partners.

Intriguingly, most of the significant differences emerged for the self-focused circumplex, where all but one of the codes significantly differed between the smooth and awkward dates. Participants had fewer separate codes on smooth dates; these codes indicate an attempt to create distance between the self and the partner by asserting one's autonomy. Participants had more disclose codes on smooth dates, which indicate a warm attempt to connect with the other person by sharing personal information, as well as more reactive love codes, which are exceptionally warm responses that indicate that the participant is enjoying the interaction (e.g., laughter). Interestingly, participants had fewer trust codes on the smooth dates relative to the awkward dates. Although trust codes are typically associated with positive interpersonal outcomes (e.g., Jørgensen, Hougaard, Rosenbaum, Valbak, \& Rehfeld, 2000), trust codes in this first date situation often indicated that the participant felt vulnerable and was relying on the partner to carry the date. Similarly, participants had fewer submit codes on the smooth dates, which frequently indicated that the participant was apathetically going along with the conversation. Finally, participants had fewer wall-off codes on the smooth dates, a code that indicates that the participant is coolly withdrawing, tuning out, or shutting down. Of the 14 associations between date smoothness and the SASB codes, two significantly differed by participant sex: Date smoothness was significantly negatively associated with separate and trust for both men and women, but this association was stronger for women.

In summary, most of the differences between the smooth and awkward dates emerged in how participants reacted to their speed-dating partners (i.e., their codes on the self circumplex) as opposed to how participants acted toward their speed-dating partners (i.e., their codes on the other circumplex). These results are presented graphically in Figure 1. In addition, the results for the individual codes clarify the absence of an overall autonomy difference between the smooth and awkward dates. Smooth dates tended to avoid both extreme autonomy codes (the top code in each circumplex) and extreme enmeshment codes (the bottom code in each circumplex), especially on the self-focused circumplex. Too much separateness and too much enmeshment may both make for an awkward first encounter.

\section{Discussion}

What behaviors make for a smooth initial romantic encounter? Rather than focusing on any one specific behavior to address this question, the present research used the broad and comprehensive SASB observational coding scheme. Regarding the three main dimensions of the SASB model, participants on smooth dates (as rated by independent coders) tended to be warmer and more other-focused than participants on awkward dates. A significant difference did not emerge on the autonomy dimension: Overall, participants were no more enmeshed or differentiated on the smooth versus the awkward dates.

One of the strengths of the SASB coding scheme is that it examines not just broad trends but also specific behaviors. Indeed, an inspection of the specific SASB codes added nuance to the dimensional findings. Despite the null finding for the autonomy dimension, autonomy differences emerged at the level of the specific code: Participants on smooth dates were more likely than those on awkward dates to avoid both the enmeshed pole and the differentiated pole of this dimension. That is, dates were smoother when participants maintained an intermediate amount of independence versus interdependence with their interaction partners. These findings illustrate the importance of examining behavior at more than one level of analysis; data analyzed at the level of the specific behavior may reveal a different story than when those same data are analyzed in aggregate. SASB lends itself well to both levels of analysis because it assesses behaviors at a fine-grained level of detail and organizes them within a broad dimensional framework.

Also intriguing was the fact that more codes significantly differed between the smooth and awkward dates on the self 
circumplex (six out of the seven non-null codes were significant) than on the other circumplex (two out of the seven nonnull codes were significant). In other words, the behaviors that mattered most in determining a date's quality were not those that characterized how participants acted toward their speeddating partners but rather the behaviors that characterized how participants reacted to their speed-dating partners. This finding is somewhat counterintuitive, as one might assume that the key ingredient for making a good impression is focusing on an interaction partner properly — grab his or her attention, use the right pickup line, and ask provocative questions (e.g., Kleinke, Meeker, \& Staneski, 1986). The present data suggest that how one reacts to the partner is perhaps even more important for achieving good romantic outcomes. Do you express yourself without boldly asserting your independence from your interaction partner? Do you react warmly without relying on the partner to maintain the flow of the date? Do you maintain an active role in the conversation and avoid withdrawing or tuning out? According to the present data, these would be some of the most important prescriptions for those who wish to have a smooth first date.

\section{Limitations and Future Directions}

One limitation of the present study is that it examined initial interactions in only a single setting: speed-dating among undergraduates. Therefore, it is possible that a smooth getting-toknow-you conversation in another context (e.g., bars, churches, classrooms) would be characterized by different behaviors. However, it is unlikely that speed-dating is an unusual or unrepresentative portrayal of initial romantic encounters, as speeddating is designed to mimic other settings where people first meet and interact with one another (Eastwick \& Finkel, 2008; Finkel, Eastwick, \& Matthews, 2007). Nevertheless, platonic initial interactions could certainly be different from romantic interactions in important ways (e.g., perhaps active love codes would not predict smooth platonic interactions); thus, it would be useful to compare platonic and romantic initial interactions in future research.

A second limitation of this research is that it did not identify the source of the differences between the smooth and awkward dates. That is, why did participants on some dates exhibit active love (i.e., flirt) with each other, whereas participants on other dates separated from each other? Was it because the speeddaters possessed skills or personality traits that caused them to engage in more of these particular behaviors, or was it because the mixture of two speed-daters' personalities happened to produce a smooth or awkward blend? Given that componential analyses typically find that healthy amounts of variance are attributable to both person-level and relationship-level variables in initial interactions (Kenny, 1994), it is likely that both explanations have some validity. However, only a social relations model analysis on all of the participants' SASB-coded speed-dates could definitively compare the magnitude of the partner-level and relationship-level contributions to interaction quality.

\section{Conclusion}

The present report used the SASB observational coding scheme to explore what behaviors differentiated smooth first dates from awkward ones. Of course, the present research does not conclusively rule out the possibility that, under certain specific circumstances, "active love" hurts one's romantic prospects (as suggested by Fein \& Schneider, 1995) or that "blame" helps one's prospects (as suggested by Strauss, 2005). But the empirical approach in this report suggests that these pop-psych recommendations are not effective tactics on average when initially getting to know someone. For empirical psychology, this analysis sketches "a map of the broader behavioral terrain" as called for by Funder (2009, p. 343), at least with respect to the predictors of interaction quality. SASB was useful in this endeavor because of its broad, comprehensive scope and its focus on actual behavior. Ultimately, SASB may prove to be a vital conceptual tool for researchers as they build the empirical base for a complete theory of interaction quality.

\section{Notes}

1. One helpful way to conceptualize the focus distinction within structural analysis of social behavior (SASB) is to consider the difference between transitive and intransitive verbs. Other-focused statements are transitive interpersonal actions, meaning that the other person is a "direct object" (e.g., "I question you", "I control you", "I protect you"), whereas self-focused statements are intransitive interpersonal actions, meaning that the other person is an "indirect object" (e.g., "I disclose to you", "I submit to you", "I trust in you"). A second way to conceptualize this distinction is that other-focused statements are prototypically "parent like" and self-focused statements are prototypically "child like" (Benjamin, Rothweiler, \& Critchfield, 2006). We use the terms act and react to refer to other and self focus, respectively (see Benjamin, 1996b; Benjamin \& Cushing, 2000), but these terms do not imply temporal sequence or cause.

2. Because the coded unit is a verbalized thought, nonverbal behavior is not measured separately from verbal behavior within the SASB system. However, coders must consider nonverbal expressions, tone of voice, and context in assigning SASB codes (Benjamin, 1996a; Benjamin \& Cushing, 2000); for example, a statement made while smiling is coded with more warmth than the same statement made while scowling.

3. For the Poisson regressions, the proportions provided by SASBWorks were transformed into a count (i.e., proportion $\times$ participant's total number of codes). Because smooth dates contained more codes on average than awkward dates $\left(M_{\text {Smooth }}=94.9\right.$ vs. $\left.M_{\text {Awkward }}=83.1\right), t(40)=2.47, p=.018$, these analyses control for the participants' total number of codes. These regressions could not converge for the emancipate and wall-off codes, and so standard multilevel regression on the proportion variables was used in these two cases.

\section{Acknowledgments}

We wish to thank the Saigal SASB-coding team (Lucy Hunt, Shreya Bansal, Joey Dadabo, Sue Kim, Shardai Kingsberry, Sara Kobaissi, 
Nicole Molenda, Arundati Nagendra, Marguerite Summer, and Amie Wolf) and the Finkel romantic-coding team (Courtney Brown, Bryn Gauer, Anand Haryani, Pedro Jimenez, Emily Kingsley-Ma, Megan Mitterer, Sarah Pickering, Drew Ratner, Ariana Rebesco, Gina Rebesco, Alex Russell, Lauren Sandberg, Jo Ellyn Walker, and Janet $\mathrm{Wu}$ ) for their hard work.

\section{Declaration of Conflict of Interest}

The authors declared that they had no conflicts of interests with respect to their authorship or the publication of this article.

\section{Financial Disclosure/Funding}

The authors declared that they received no financial support for their research and/or authorship of this article.

\section{References}

Altman, I., \& Taylor, D. A. (1973). Social penetration: The development of interpersonal relationships. New York, NY: Holt, Rinehart \& Winston.

Aron, A., Melinat, E., Aron, E. N., Vallone, R. D., \& Bator, R. J. (1997). The experimental generation of interpersonal closeness: A procedure and some preliminary findings. Personality and Social Psychology Bulletin, 23, 363-377.

Benjamin, L. S. (1974). Structural analysis of social behavior. Psychological Review, 81, 392-425.

Benjamin, L. S. (1996a). A clinician-friendly version of the interpersonal circumplex: Structural analysis of social behavior (SASB). Journal of Personality Assessment, 66, 248-266.

Benjamin, L. S. (1996b). Interpersonal diagnosis and treatment of personality disorders. (2nd ed.). New York, NY: Guilford.

Benjamin, L. S. (2000). SASB Intrex questionnaires \& software [Computer software]. Salt Lake City: University of Utah.

Benjamin, L. S., \& Cushing, G. (2000). Reference manual for coding social interactions in terms of structural analysis of social behavior. Salt Lake City: University of Utah.

Benjamin, L. S., Rothweiler, J. C., \& Critchfield, K. L. (2006). The use of structural analysis of social behavior (SASB) as an assessment tool. Annual Review of Clinical Psychology, 2, 83-109.

Berry, D. S., \& Hansen, J. S. (2000). Personality, nonverbal behavior, and interaction quality in female dyads. Personality and Social Psychology Bulletin, 26, 278-292.

Brown, P. C., \& Smith, T. W. (1992). Social influence, marriage, and the heart: Cardiovascular consequences of interpersonal control in husbands and wives. Health Psychology, 11, 88-96.

Chartrand, T. L., \& Bargh, J. A. (1999). The chameleon effect: The perception-behavior link and social interaction. Journal of Personality and Social Psychology, 76, 893-910.

Collins, N. L., \& Miller, L. C. (1994). Self-disclosure and liking: A meta-analytic review. Psychological Bulletin, 116, 457-475.

Duck, S., Rutt, D. J., Hurst, M. H., \& Strejc, H. (1991). Some evident truths about everyday conversation: All communications are not created equal. Human Communication Research, 18, 228-267.

Eastwick, P. W., \& Finkel, E. J. (2008). Speed-dating: A powerful and flexible paradigm for studying romantic relationship initiation. In S. Sprecher, A. Wenzel, \& J. Harvey (Eds.), The handbook of relationship initiation (pp. 217-234). Mahwah, NJ: Lawrence Erlbaum.

Fein, E., \& Schneider, S. (1995). The rules: Time-tested secrets for capturing the heart of Mr. Right: New York, NY: Warner Books.

Finkel, E. J., Campbell, W. K., Brunell, A. B., Dalton, A. N., Scarbeck, S. J., \& Chartrand, T. L. (2006). High-maintenance interaction: Inefficient social coordination impairs self-regulation. Journal of Personality and Social Psychology, 91, 456-475.

Finkel, E. J., Eastwick, P. W., \& Matthews, J. (2007). Speeddating as an invaluable tool for studying initial romantic attraction: A methodological primer. Personal Relationships, 14, 149-166.

Florsheim, P., \& Benjamin, L. S. (2001). The structural analysis of social behavior observational coding scheme. In P. K. Kerig \& K. M. Lindahl (Eds.), Family observational coding systems: Resources for systematic research (pp. 127-150). Mahwah, NJ: Lawrence Erlbaum.

Florsheim, P., Tolan, P. H., \& Gorman-Smith, D. (1996). Family processes and risk for externalizing behavior problems among African American and Hispanic boys. Journal of Consulting and Clinical Psychology, 64, 1222-1230.

Funder, D. C. (2009). Naïve and obvious questions. Perspectives in Psychological Science, 4, 340-344.

Goffman, E. (1959). The presentation of self in everyday life. New York, NY: Doubleday.

Gonzaga, G. C., Keltner, D., Londahl, E. A., \& Smith, M. D. (2001). Love and the commitment problem in romantic relations and friendship. Journal of Personality and Social Psychology, 81, 247-262.

Gottman, J. M., \& Levenson, R. W. (1992). Marital processes predictive of later dissolution: Behavior, physiology, and health. Journal of Personality and Social Psychology, 63, 221-233.

Haddock, C. K., Rindskopf, D., \& Shadish, W. R. (1998). Using odds ratios as effect sizes for meta-analysis of dichotomous data: A primer on methods and issues. Psychological Methods, 3, 339-353.

Humes, D. L., \& Humphrey, L. L. (1994). A multimethod analysis of families with a polydrug-dependent or normal adolescent daughter. Journal of Abnormal Psychology, 103, 676-685.

Humphrey, L. L., \& Benjamin, L. S. (1989). The structural analysis of social behavior observational coding scheme. Unpublished manual, Northwestern University Medical School, Chicago.

Jones, E. E. (1990). Interpersonal perception. New York, NY: Freeman.

Jones, E. E., \& Wortman, C. (1973). Ingratiation: An attributional approach. Morristown, NJ: General Learning Press.

Jørgensen, C., Hougaard, E., Rosenbaum, B., Valbak, K., \& Rehfeld, E. (2000). The dynamic assessment interview (DAI), interpersonal process measured by structural analysis of social behavior (SASB) and therapeutic outcome. Psychotherapy Research, 10, 181-195.

Kenny, D. A. (1994). Interpersonal perception: A social relations analysis. New York, NY: Guilford.

Kleinke, C. L., Meeker, F. B., \& Staneski, R. A. (1986). Preference for opening lines: Comparing ratings by men and women. Sex Roles, $15,585-600$. 
Leary, T. (1957). Interpersonal diagnosis of personality: A functional theory and methodology for personality evaluation. New York, NY: Ronald Press.

Locke, K. D. (2000). Circumplex scales of interpersonal values: Reliability, validity, and applicability to interpersonal problems and personality disorders. Journal of Personality Assessment, 75, 249-267.

Markey, P. M., Funder, D. C., \& Ozer, D. J. (2003). Complementarity of interpersonal behaviors in dyadic interactions. Personality and Social Psychology Bulletin, 29, 1082-1090.

Schlenker, B. R., \& Leary, M. R. (1982). Social anxiety and self-presentation: A conceptualization and model. Psychological Bulletin, 92, 641-669.

Sedikides, C. (1993). Assessment, enhancement, and verification determinants of the self-evaluation process. Journal of Personality and Social Psychology, 65, 317-338.

Sedikides, C., Campbell, W. K., Reeder, G. D., \& Elliot, A. J. (1999). The relationship closeness induction task. Representative Research in Social Psychology, 23, 1-4.

Singelis, T. M. (1994). The measurement of independent and interdependent self-construals. Personality and Social Psychology Bulletin, 20, 580-591.

Snyder, M. (1992). Motivational foundations of behavioral confirmation. In M. P. Zanna (Ed.), Advances in experimental social psychology (Vol. 25, pp. 67-114). Orlando, FL: Academic Press.

Snyder, M., \& Haugen, J. (1995). Why does behavioral confirmation occur? A functional perspective on the role of the target. Personality and Social Psychology Bulletin, 21, 963-974.
Sprecher, S., \& Duck, S. (1994). Sweet talk: The importance of perceived communication for romantic and friendship attraction experienced during a get-acquainted date. Personality and Social Psychology Bulletin, 20, 391-400.

Strauss, N. (2005). The game: Penetrating the secret society of pickup artists. New York, NY: HarperCollins.

Sunnafrank, M. (1988). Predicted outcome value in initial conversations. Communication Research Reports, 5, 169-172.

Tice, D. M., Butler, J. L., Muraven, M. B., \& Stillwell, A. M. (1995). When modesty prevails: Differential favorability of selfpresentation to friends and strangers. Journal of Personality and Social Psychology, 69, 1120-1138.

Vohs, K. D., Baumeister, R. F., \& Ciarocco, N. J. (2005). Selfregulation and self-presentation: Regulatory resource depletion impairs impression management and effortful self-presentation depletes regulatory resources. Journal of Personality and Social Psychology, 88, 632-657.

\section{Bios}

Paul W. Eastwick is an assistant professor at Texas A\&M University in the department of Psychology.

Seema D. Saigal is a $\mathrm{PhD}$ candidate in the clinical psychology program at Northwestern University and a clinical instructor at Texas A\&M University in the department of Psychology.

Eli J. Finkel is an associate professor at Northwestern University in the department of Psychology. 